Fournal of Medical Genetics (1976). 13, 501-506.

\title{
Abnormal chromosome 22 and recurrence of trisomy-22 syndrome*
}

\author{
BEVERLY S. EMANUEL, ELAINE H. ZACKAI, MARGARET M. ARONSON, \\ WILLIAM J. MELLMAN, and PAUL S. MOORHEAD
}

\begin{abstract}
From The Children's Hospital of Philadelphia, University of Pennsylvania Human Genetics Center, Department of Human Genetics, University of Pennsylvania School of Medicine; Philadelphia, Pennsylvania, 19104; and the Institute for Medical Research, Camden, New fersey 08103, USA
\end{abstract}

\begin{abstract}
Summary. Trisomy-22 was confirmed with both Q- and G-banding in two sibs. Growth and mental retardation plus various dysmorphic features of this syndrome are described and compared with previous reports. Cytogenetic studies reveal a morphologically atypical No. 22 in cells of the phenotypically normal mother $(46, \mathrm{XX})$ and in both affected children. The variant $\mathrm{G}$ chromosome is identified as No. 22 by Q- and G-banding and is interpreted as a product of a pericentric inversion on the basis of general length, arm ratio (1.4), and anomalous satellite association frequency. Repeated nondisjunction for No. 22 is considered to have resulted from asynapsis caused by interference in formation of an inversion loop configuration which, though short, comprised a major part of chromosome 22 .
\end{abstract}

Trisomy-22 syndrome is a rare clinical condition usually diagnosed on finding an extra G chromosome in patients with multiple congenital anomalies who lack the clinical manifestations of Down's syndrome (Goodman et al, 1971; Hsu et al, 1971; Nielson et al, 1969; Gustavson, Hitrec, and Santesson, 1972; Uchida et al, 1968). Conventional preparations cannot provide a distinction between members of the $G$ group, whereas current techniques for $\mathrm{G}$ - and Q-banding can give specific identifications of 21 and 22 (Punnett et al, 1973; Bass, Crandall, and Sparkes, 1973). To our knowledge the family reported here is the first instance of sibs being diagnosed as trisomy-22 by G- and Qbanding techniques. A second instance of the recurrence of trisomy-22 in a family has recently been reported. Degenhardt et al (1975) report the positive banding identification of trisomy-22 in sibs and, as in the report here, a pericentric inversion is also involved.

In seeking an explanation for recurrence of this rare trisomic condition within a family, we found that the cells of both sibs, and of the mother, con-

Received 23 February 1976.

* This research supported in part by funds from USPHS grants GRS-4-99-939, HD-06323, and GM 20138. tained one No. 22 which was more metacentric than the normal 22. Other authors have proposed that there may be an increased frequency of non-disjunction in families in which a $G$ or $D$ chromosome with abnormal short arms or satellites is segregating (Cooper and Hirschhorn, 1962; Therkelson, 1964; DeGrouchy et al, 1964). Cytogenetic studies of this family were undertaken to clarify the nature of this atypical chromosome and its possible role in non-disjunction.

\section{Case histories}

Case 1. The propositus (Fig. 1) was a 3-week-old white female examined because of physical anomalies similar to those of her severely retarded 5-year-old male sib. She was born at term to a 34-year-old mother and a 36-year-old father (birthweight $2820 \mathrm{~g}$ ). She developed congestive heart failure at 2 weeks of age. At that time she was found to have micrognathia, high arched palate, left preauricular sinus, low set right ear, low set nipples, and tight anal sphincter. Reflexes were poor. Dermatoglyphs were not unusual. Cardiac catheterization revealed preligamentary coarctation of the aorta with a long hypoplastic segment of the isthmus. $X$-ray examination showed 13 pairs of ribs. She died of heart failure at age 6 weeks. Necropsy revealed these additional findings: persistent left superior vena cava, atrial 


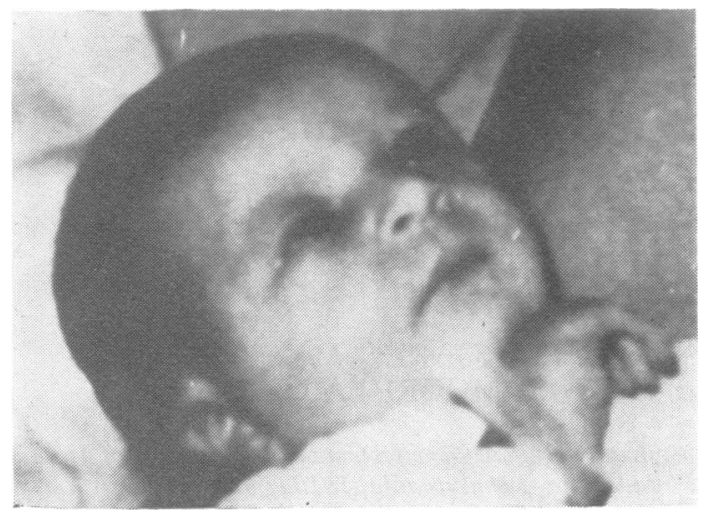

FIg. 1. Propositus (Case 1) at age 1 week.

septal defect, single umbilical artery, intrathyroid position of parathyroid glands, hypoplasia of corticospinal tracts, and cerebellar dysplasia.

Case 2. The 5-year-old brother of the propositus was severely retarded (Fig. 2). He was born at term (birthweight $2840 \mathrm{~g}$ ). Anomalies noted were: prominent forehead, cleft palate, left preauricular sinus, preauricular skin tags, dislocated left hip, small phallus, inguinal testes, imperforate anus, and 13 pairs of ribs. At age $2 \frac{1}{2}$ he was placed in an institution; his developmental quotient was 50. At age 4 years 11 months he was noted to be severely retarded, short dwarfed (height $90.0 \mathrm{~cm}$ ), and microcephalic (head circumference $47.5 \mathrm{~cm}$ ). An inguinal hernia had been repaired and he was noted to have acyanotic heart disease (?VSD).

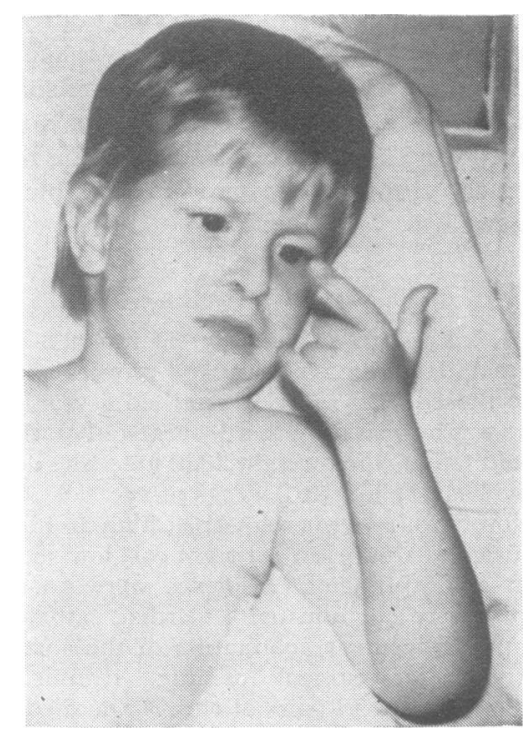

FIG. 2. Older sib of propositus (Case 2) at age $5 \frac{1}{2}$ years.
There was one other pregnancy in this family, a normal $2 \frac{1}{2}$-year-old male. The parents deny consanguinity and there are no other family members with congenital malformations. Both parents are phenotypically normal.

\section{Methods}

\section{Cytogenetic studies}

Chromosome preparations were made from PHAstimulated leucocyte cultures (Moorhead et al, 1960). Differential staining, G-banding (Seabright, 1971) and Q-banding (Caspersson, Zech, and Johansson, 1970), was applied to chromosome slide preparations made by air-drying.

Arm ratio and chromosome length measurements were made on the $\mathrm{G}$ chromosomes of 13 randomly selected metaphase cells from the mother using conventional Giemsa-stained material. Negatives were projected $(17000 \times)$ and linear tracings of the G-group chromosomes were made for caliper measurements along the axis of each chromatid, excluding satellites.

A score of the total number of G-group chromosomes involved in satellite associations ( 0 to 4 ) was obtained for 100 cells. Positive associations were those in which the distance between the base of the short arm of one chromosome to the same point on the other did not exceed the length of any G chromosome in that cell. The frequency of nonspecific associations was determined in 50 cells by scoring the number of similarly sized, but unsatellited, $\mathrm{F}$ chromosomes which fit the above criterion for association.

\section{Results}

\section{Karyology}

Karyotypes of Cases 1 and 2 prepared from conventional Giemsa-stained material contained 47 chromosomes with an extra G-group chromosome. In cells from both patients one $G$ chromosome was noted to be more metacentric than expected (Fig. 3 and 4). Karyotypes of the father and the normal male sib revealed normal $46, \mathrm{XY}$ complements by standard staining and also by G- and Qbanding.

The mother's cells had a 46,XX karyotype with an atypical G chromosome, apparently identical to the one found in both affected offspring (Fig. 5). Gbanding of the mother's chromosome showed two normally banded 21 's, one normally banded 22 chromosome, and the variant chromosome (Fig. 6). By its G-banding pattern and by its morphology in conventionally stained preparations (Fig. 7) the atypical chromosome is apparently a rearranged No. 22. 

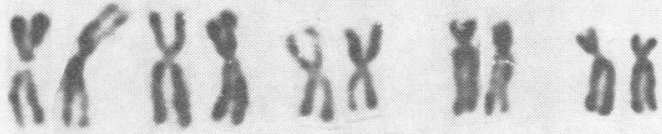

1

2
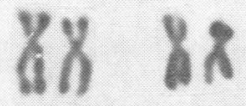

6

$\mathrm{X}$
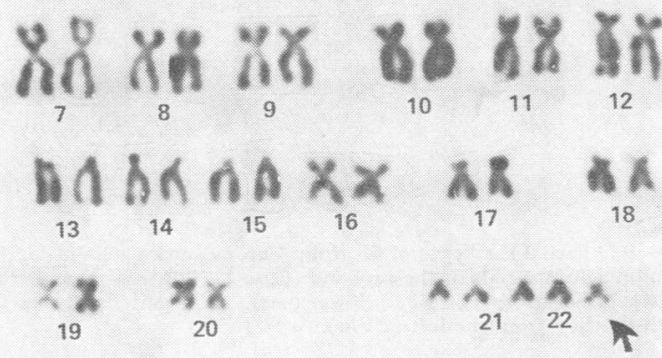

FIG. 3. Karyotype from conventional preparation of cultured leucocytes of propositus (Case 1). (Arrow denotes the atypical G chromosome.)

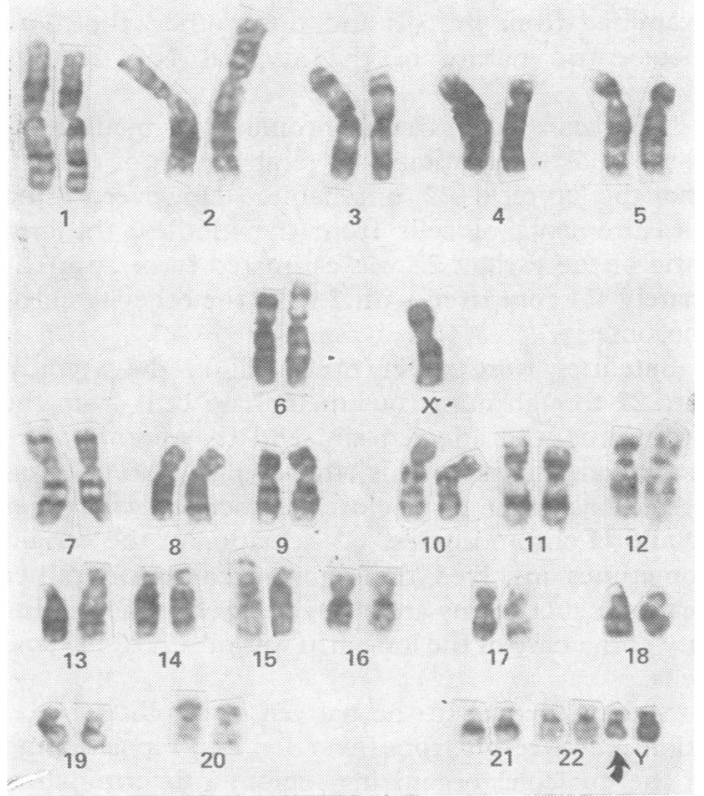

FIG. 4. Karyotype of brother (Case 2) of propositus from G-banding preparation of cultured leucocytes. (Arrow denotes the atypical $G$ chromosome.)
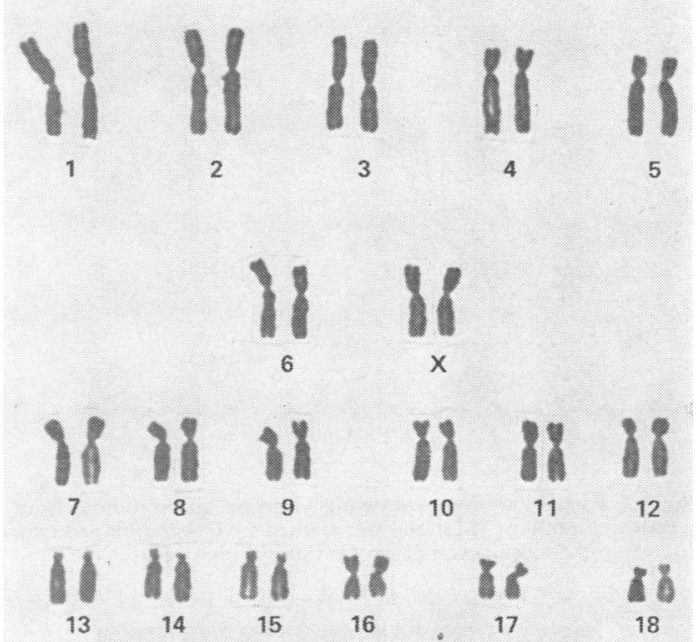
82

\section{8}
20

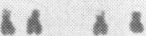
2122 个

FIG. 5. Karyotype of mother of the two patients (Case 1 and 2), from a conventional preparation of cultured leucocytes. (Arrow denotes the atypical $\mathrm{G}$ chromosome.)
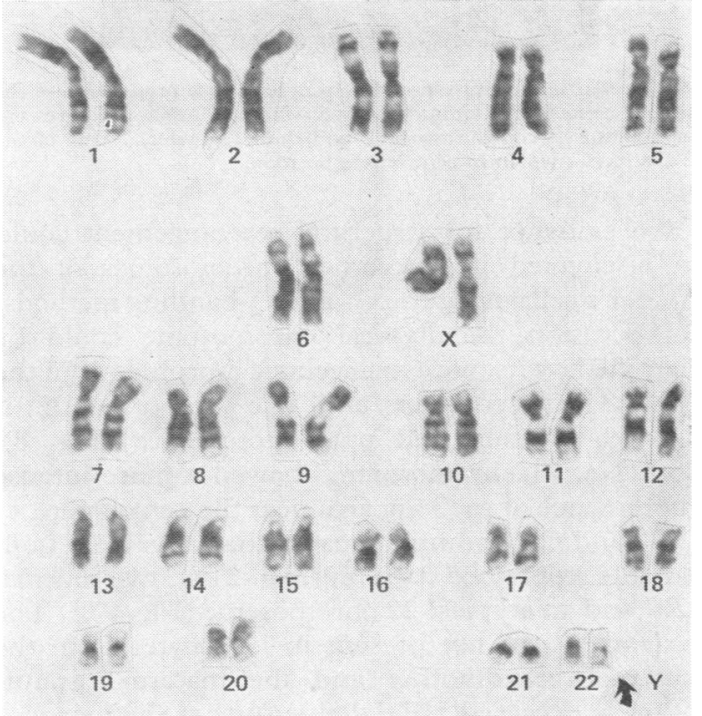

FIG. 6. Karyotype of mother from G-banded preparation of cultured leucocytes. (Arrow denotes the atypical $G$ chromosome.) 


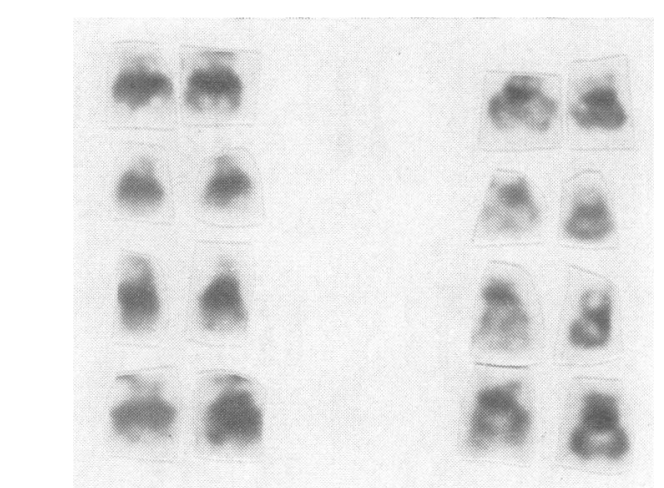

FIG. 7. Partial karyotypes showing $\mathrm{G}$ group chromosomes from 4 cells of the mother. Material was stained by G-banding procedure. The variant 22 chromosome is at far right in each group.

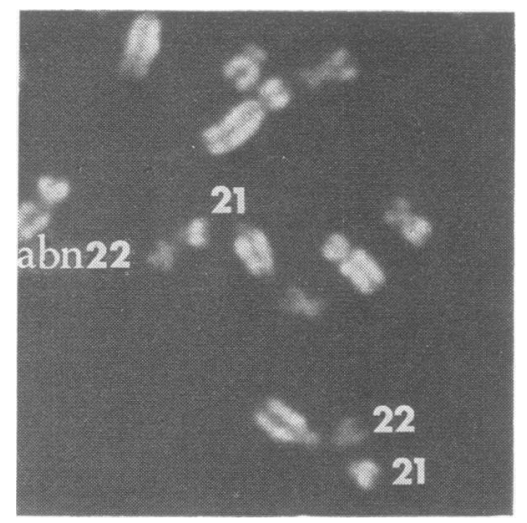

FIG. 8. Partial metaphase spread from leucocyte preparation of the mother stained with quinicrine hydrochloride to show fluorescent distinction between the two 21's and the 22's (paler). One of the 22 's is more median in centromere position.

No evidence for structural rearrangement could be discovered in any other chromosomes of the mother's cells using the G- and Q-banding methods. On occasion the atypical chromosome could be identified by its more metacentric morphology in the Q-banded preparations and, like the normal 22, it showed a generalized pale fluorescence (Fig. 8). Both No. 21 chromosomes showed a more intense fluorescence of the long arm near the centromere.

G- and Q-banding indicated that cells from both patients contained two normal 21's, two normal 22's, and an atypical 22 chromosome (Fig. 9). The variant 22 was not present in leucocytes from the maternal grandmother and the maternal grandfather is deceased. To define further the morphology of this atypical 22, other studies of the G group chromosomes of the mother's cells were undertaken.

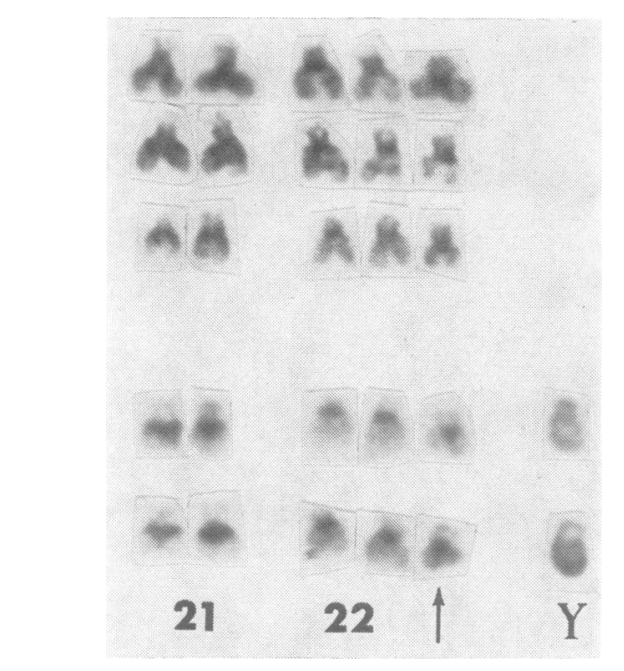

FIG. 9. Partial karotypes of $\mathrm{G}$ group chromosomes stained for Gbanding from 3 cells of the proband (Case 1) (upper part) and from 2 cells of her brother (Case 2) (lower part). The variant 22 is in the fifth position from the left (arrow).

In the propositus observations of less condensed chromosomes in cells of early metaphase indicated that the anomalous No. 22 was similar in length, or slightly shorter than, the normal $G$ chromosomes. In cells of the propositus, and in nearly all cells examined from the sib and the mother, the morece metacentric nature of the atypical No. 22 was? obvious.

The small size of the $\mathrm{G}$ chromosomes made comparative determinations of overall length of the G's and the atypical 22 unreliable. However, using measurements of cells from the mother, the arm ratio of the variant 22 was estimated to be approximately 1.4 compared with 2.9 for the other G chromosomes.

Satellites were never observed on the atypical No. 22 though numerous metaphase cells from the propositus, the affected sib, and the mother were examined. Despite this, the atypical No. 22 was occasionally seen to be closely associated with other $\mathrm{D}$ and $\mathrm{G}$ chromosomes. Association of the variant sometimes involved the centromere region rather than the short arms and a segment of reduced density at the base of the long arm was observed in some cells.

Since a change in the pattern of satellite association might result from inversion and repositioning of the nucleolar organizing region, a determination of satellite association was made.

From 100 metaphase cells of the mother, $400 \mathrm{G}$ group chromosomes were scored for satellite 
associations and 225 were noted to be so involved with another $\mathrm{G}$ or $\mathrm{D}$ chromosome. Among 100 atypical $G$ chromosomes, only 28 were positively associated. Of the 300 normal $G$ chromosomes, 197 were associated $(66 \%)$. These observations depart significantly from expectations based upon equal probabilities, wherein 56 atypical G's and 169 (of 300) of the normal G's would be associated. Observations of $200 \mathrm{~F}$ group chromosomes for random association disclosed only 8 which warranted scoring as positive in association $(4 \%)$ with a $\mathrm{D}$ or $\mathrm{G}$ chromosome. The observed frequency of association for the atypical No. 22 chromosome $(28 \%)$ is, therefore, greater than the result of nonspecific association $(4 \%)$ and yet is significantly less than that observed for any of the 3 normal G chromosomes $(66 \%)$.

\section{Discussion}

The diagnosis of trisomy-22 was confirmed in two sibs by G- and Q-banding. One of the G-group chromosomes is morphologically atypical and is identified as a No. 22 inherited from the phenotypically normal mother.

Several authors have described non-mongoloid individuals with an extra small acrocentric chromosome. Though the phenotypes of these individuals have varied widely, their similarities have resulted in the description of a trisomy 22 syndrome (Goodman et al, 1971; Hsu et al, 1971; Nielson et al, 1969). Punnett et al (1973) have urged banding studies in all such patients because the extra chromosome in some was not morphologically normal.

Clinical abnormalities seen in both the sibs reported here were: preauricular skin tags or sinuses, palate anomaly (high arched or cleft), cardiac defect (coarctation of aorta, ventricular septal defect), anal anomaly (imperforate anus, tight anal sphincter), and 13 pairs of ribs. Features observed in only one of these patients include: micrognathia, low set nipples, low set ears, hip dislocation, microcephaly, and small phallus. Growth and mental retardation were seen in Case 2, who survived infancy. With the exception of the 13 pairs of ribs, these anomalies have been reported in other cases of presumed, or definitely identified, trisomy-22 (Goodman et al, 1971; Hsu et al, 1971; Nielson et al, 1969; Gustavson et al, 1972; Uchida et al, 1968; Punnett et al, 1973; Bass et al, 1973; Degenhardt et al, 1975). Cases of trisomy-22 have also been reported with abnormal insertion of thumbs, and kidney anomalies (Punnett et al, 1973; Degenhardt et al, 1975).

This family seems predisposed to non-disjunction of the No. 22 chromosome though the parents are not at risk because of advanced age nor do they carry any detectable translocation. The mother carries the same variant No. 22 seen in both trisomic offspring but since she is phenotypically normal her genome is assumed to be complete. The atypical 22 she carries is similar in length to her other G group chromosomes and is probably not the product of a translocation. Frequency of satellite association of the variant chromosome in the mother is significantly reduced but is definitely not absent. This may reflect a change in function or compaction of the nucleolar organizing region, a result of its being repositioned within the chromosome.

A final definition of the rearrangement involved in the origin of this variant 22 remains inconclusive. However, the lack of apparent involvement of banded regions elsewhere in the karyotype, the apparently normal length of the variant 22 , its altered arm ratio, and its anomalous association with satellited chromosomes suggest a pericentric inversion as the least complex explanation. Within the constraints of the size of chromosome 22 and the few landmarks available, it is conjectured that one break point of an inversion occurred in the satellite or stalk of the short arm of 22 and the other just distal to the positive $G$ band in region $22 q 12$. The origin of the inversion could not be fixed within the pedigree beyond the fact that the maternal grandmother was karyologically normal with no variant- 22 and the maternal grandfather deceased.

According to Hamerton (1971a) non-disjunction is most likely to occur at the first meiotic division as a result of abnormal homologue pairing. The presence of a pericentric inversion generally does not enhance the frequency of non-disjunction (Wahrman et al, 1972). However, where the inverted segment is short in absolute length, as in the present case, physical constraints on loop formation and, therefore, of effective synapsis would be more likely (White, 1973). Risk of non-disjunction is further enhanced by the fact that this putative inversion involves a considerable proportion of the overall length of chromosome No. 22. Asynapsis of the inverted segments would leave only the two small segments outside the limits of the inversion to contribute to the pairing forces. Hamerton (1971b) has suggested that the frequency of non-disjunction may be increased in families in which a $\mathrm{D}$ or $\mathrm{G}$ chromosome with abnormal short arms is segregating and that individuals with 'minor chromosome variants' are at greater risk of meiotic error.

Although trisomy-22 is itself relatively rare, 3 reports of this condition in which one of the 22's is morphologically atypical (Punnett et al, 1973; Bass et al, 1973; Degenhardt et al, 1975). In all 3 instances the atypical 22 was carried as a marker in the 
unaffected mother and in other phenotypically normal family members. The report by Degenhardt et al (1975) describes a family almost identical to the present one, where repeated non-disjunction has affected two sibs, and the atypical 22 is also interpreted as the result of a pericentric inversion. It, therefore, seems imperative that detailed chromosomal studies using the banding techniques for detection and identification of rearrangement be applied to families which bear 'variants' of the small acrocentrics.

The authors acknowledge the excellent technical assistance of Mr James Loftus of the Children's Hospital of Philadelphia.

\section{REFERENCES}

Bass, H. N., Crandall, B. F., and Sparkes, R. S. (1973). Probable trisomy 22 identified by fluorescent and Trypsin-Giemsa banding. Annales de Génétique, 16, No. 3, 189-192.

Caspersson, T., Zech, L., and Johansson, C. (1970). Differential binding of alkylating fluorochromes in human chromosomes. Experimental Cell Research, 60, 315-319.

Cooper, H. L. and Hirschhorn, K. (1962). Enlarged satellites as a familial chromosome marker. American fournal of Human Genetics, 14, 107-124.

Degenhardt, K. H., Geisler, M., Weisse, K., and Grubisic, A. (1975). The mental retardation syndrome G 22 (abstract). In Amer. Soc. Human Genetics, 27th Annual Meeting, 1975.

DeGrouchy, J., Thieffry, S., Arthuis, M., Gerbeaux, J., Poupinet, S., Salmon, C., and Lamy, M. (1964). Chromosome margreurs familiaux et aneuploidie. Role possible de li interaction chromosomique. Annales de Génétique, 7, 76-83.

Goodman, R. M., Spero, M., Skaki, R., Padeli, B., and Sadan, N. (1971). The question of trisomy 22 syndrome. fournal of Pediatrics, 79, 174-175.

Gustavson, K. H., Hitrec, V., and Santesson, B. (1972). Three nonmongoloid patients of similar phenotype with an extra G-like chromosome. Clinical Genetics, 3, 135-146.

Hamerton, J. L. (1971a). Human Cytogenetics, Vol. I. General Cytegenetics, pp. 198-200. Academic Press, New York.

Hamerton, J. L. (1971b). Human Cytogenetics, Vol. 1. General Cytogenetics, p. 129. Academic Press, New York.

Hsu, L., Shapiro, L. R., Gertner, M., Lieber, E., and Hirschorn, K. (1971). Trisomy 22: a clinical entity. Fournal of Pediatrics, 79, 12-19.

Moorhead, P. S., Nowell, P. C., Mellman, W. J., Battips, D. M., and Hungerford, D. A. (1960). Chromosome preparations of leukocytes cultured from human peripheral blood. Experimental Cell Research, 20, 613-616.

Nielson, J., Tsuboi, T., Friedrick, U., Mikkelsen, M., Lund, B., and Steinicke, O. (1969). Additional small acrocentric chromosomes: two cases. Fournal of Mental Deficiency Research, 13, 106-122.

Punnett, H. H., Kistenmacher, M. L., Toro-Sola, M. A., and Kohn, G. (1973). Quinacrine fluorescence and Giemsa banding in trisomy 22. Theoretical and Applied Genetics, 43, 134-138.

Seabright, M. (1971). A rapid banding technique for human chromosomes. Lancet, 2, 971-972.

Therkelson, A. J. (1964). Enlarged short arm of a small acrocentric chromosome in grandfather, mother and child, the latter with Down's syndrome. Cytogenetics, 3, 441-451.

Uchida, A. I., Ray, M., McRae, K. N., and Besant, D. F. (1968). Familial occurrence of trisomy 22. American fournal of Human Genetics, 20, 107-118.

Wahrman, J., Atidia, J., Goiten, R., and Cohen, T. (1972). Pericentric inversions of chromosome 9 in two families. Cytogenetics, 11, 132-144.

White, M. J. D. (1973). Animal Cytology and Evolution, 3rd ed., p. 215. Cambridge University Press, Cambridge. 